\title{
Breast cancer in Mongolia: an increasingly important health policy issue
}

This article was published in the following Dove Press journal:

Breast Cancer - Targets and Therapy

20 January 2017

Number of times this article has been viewed

\section{Delgermaa Demchig \\ Claudia Mello-Thoms \\ Patrick C Brennan \\ Medical Image Optimization and Perception Group (MIOPeG), Faculty of Health Science, The University of Sydney, Sydney, NSW, Australia}

\begin{abstract}
Breast cancer is a leading cause of cancer-related death for women in both developed and developing countries. The incidence and mortality of breast cancer in Mongolia, while low compared with other counties, has been increasing on an annual basis. In addition, in Mongolia, approximately $90 \%$ of the patients are diagnosed at a late stage, resulting in high mortality, with the majority of individuals diagnosed with breast cancer dying within 5 years of diagnosis. Breast cancer screening plays an important role in reducing mortality in Western countries and has been adopted by a number of Asian countries; however, no such approach exists in Mongolia. In a country of limited resources, implementation of expensive health strategies such as screening requires effective allocations of resources and the identification of the most effective imaging methods. This requirement relies on recent accurate data; however, at this time, there is a paucity of information around breast cancer in Mongolia. Until data around features of the disease are available, effective strategies to diagnose breast cancer that recognize the economic climate in Mongolia cannot be implemented and the impact of breast cancer is likely to increase.
\end{abstract}

Keywords: incidence, mortality, breast screening, Mongolia

\section{Data source and material}

The data used in this review mainly arose from 2 sources; the Cancer Registry, located in the National Cancer Center (NCC) in Mongolia, ${ }^{1}$ and the International Association of Cancer Research (IACR). ${ }^{2}$ The Cancer Registry in Mongolia was initiated as a hospitalbased registry at the NCC in the early 1960 s and has now developed as a populationbased registry, ${ }^{3}$ where data on incidence and mortality of breast cancer between 2009 and 2013 are available. All newly diagnosed cancer and death cases along with the personal and clinical information are recorded at the primary- and secondary-level hospitals and submitted to the Cancer Registry via Health info- 2 software. ${ }^{4}$

The quality of the data in Mongolia is not clear, as data collection relies on certain factors such as population coverage and collection method. For example, the limited availability of health facilities and trained health professionals in rural areas may result in a number of cancer cases not being diagnosed and many deaths not being recorded. Also, the comprehensiveness of the data is not well understood since histology and morphology records have only become available since $2012 .{ }^{4}$

\section{Introduction}

Breast cancer remains the major health concern since it is the most common cancer among women in the world. ${ }^{2,5}$ The rates in incidence and mortality, however, vary 
significantly by region. In general, developed nations demonstrate a greater incidence (greater than 80 per 100,000) compared with developing countries (less than 30 per $100,000)$, although the latter group is currently demonstrating more rapid increases in incidence. ${ }^{6}$ Women in low- and middle-income countries tend to be diagnosed at late stages largely due to lack of available routine mammographic screening and breast cancer awareness. ${ }^{7,8}$ In such low resource countries, research data are needed to understand the impact and tailoring of limited resources to maximize impacts on breast cancer. ${ }^{9-11}$

Mongolia, with a population of 3 million, is one of the fastest developing countries in Asia, but encounters a substantial and unique cancer burden nationwide. While liver cancer is almost 4 times higher than the world average, being by far the most common cancer among both sexes, ${ }^{3}$ breast cancer is the 5 th most common primary cancer among Mongolian women with a current rate of 6 per 100,000 women, accounting for $6 \%$ of all new cases of female cancer. ${ }^{1}$ Despite these low figures, the incidence rate appears to be increasing on an annual basis. ${ }^{1,12}$ Also, since the majority of cancer patients are diagnosed at a relatively late stage, the disease has become a serious public health issue. ${ }^{13,14}$

It should be acknowledged from the outset that in Mongolia, details on the incidence, nature and mortality around breast cancer, along with information on type of women affected are limited and without such data, future health policies or systems around this disease cannot be strategically planned or implemented. This review aims to bring together the available data and provide an overview of the current status of breast cancer epidemiology in Mongolia. The data will be presented in the context of what is known about the disease in Asian countries and westernized populations.

\section{Breast cancer incidence}

While Mongolia has a relatively low breast cancer incidence rate, this value has been consistently increasing. An examination of the annual cancer registry in Mongolia between 2009 and 2013, which contains some of the most recent breast cancer data (Figure 1), demonstrated a substantial increase in the breast cancer incidence rate from 3.0 in 2009 to 6.0 in 2013. ${ }^{1}$ However, the year on year increase was inconsistent, with the most rapid increase of 54\% seen in the 2009-2010 period resulting in incidence rates of 3.0 and 4.6 per 100,000 in 2009 and 2010, respectively. An increasing trend in breast cancer has also been reported earlier by Troisi et al, ${ }^{12}$ based on data between 1998 and 2005 from the IACR and the NCC in Mongolia.

As noted in other Asian countries, incidence rates within Mongolia vary by geographical regions (Figure 2). For example, some rural provinces of Khentii and Bayan-Ulgii have considerably higher rates of 10.1 and 11.0/100,000, respectively, compared with the national level at 6.0/100,000, ${ }^{1}$ and it is interesting to note that these provinces are the home for most of the ethnic minorities of Mongolia. Such ethnicdependent variation in incidence (and presentation) of breast cancer has been reported in the neighboring country of People's Republic of China. ${ }^{15}$ Although the cancer registry is

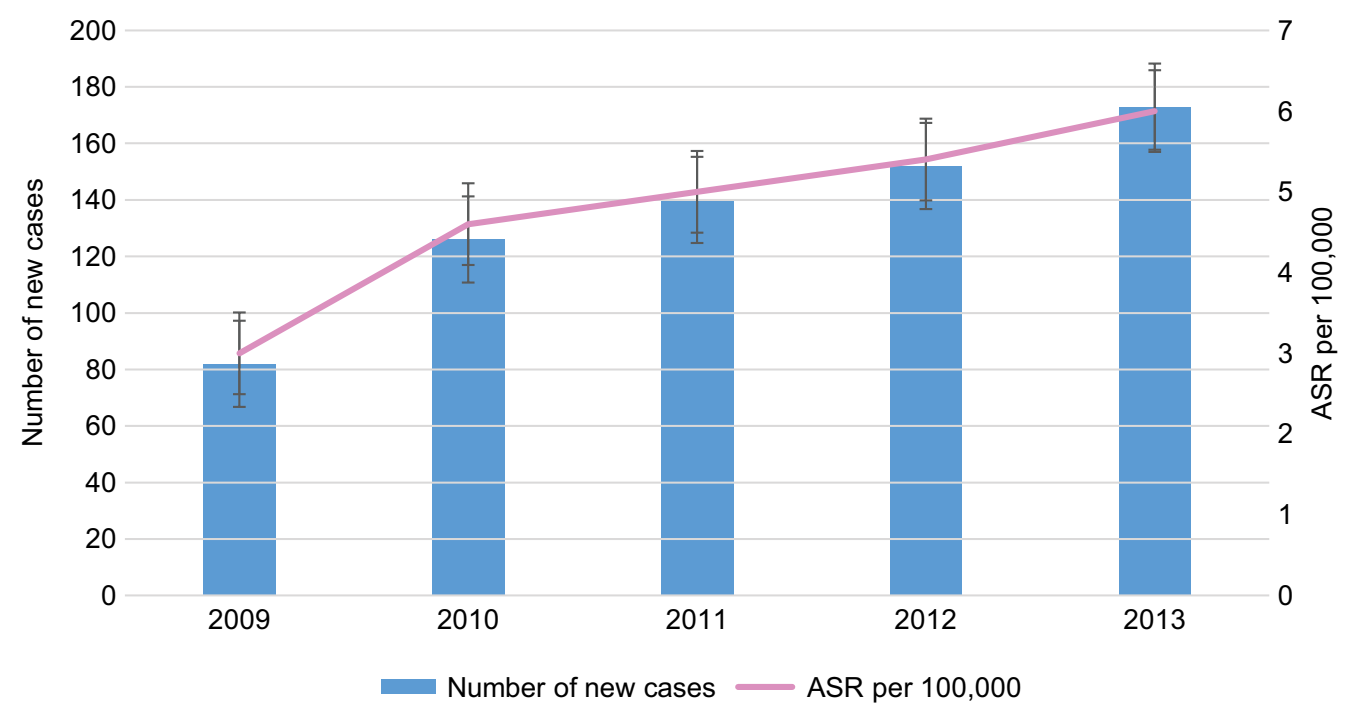

Figure I Incidence rate of female breast cancer, Mongolia, 2009-20I3.

Note: Data from Cancer Registry Data, National Cancer Center, Mongolia, 2009-2013.'

Abbreviation: ASR, age-standardized rate. 


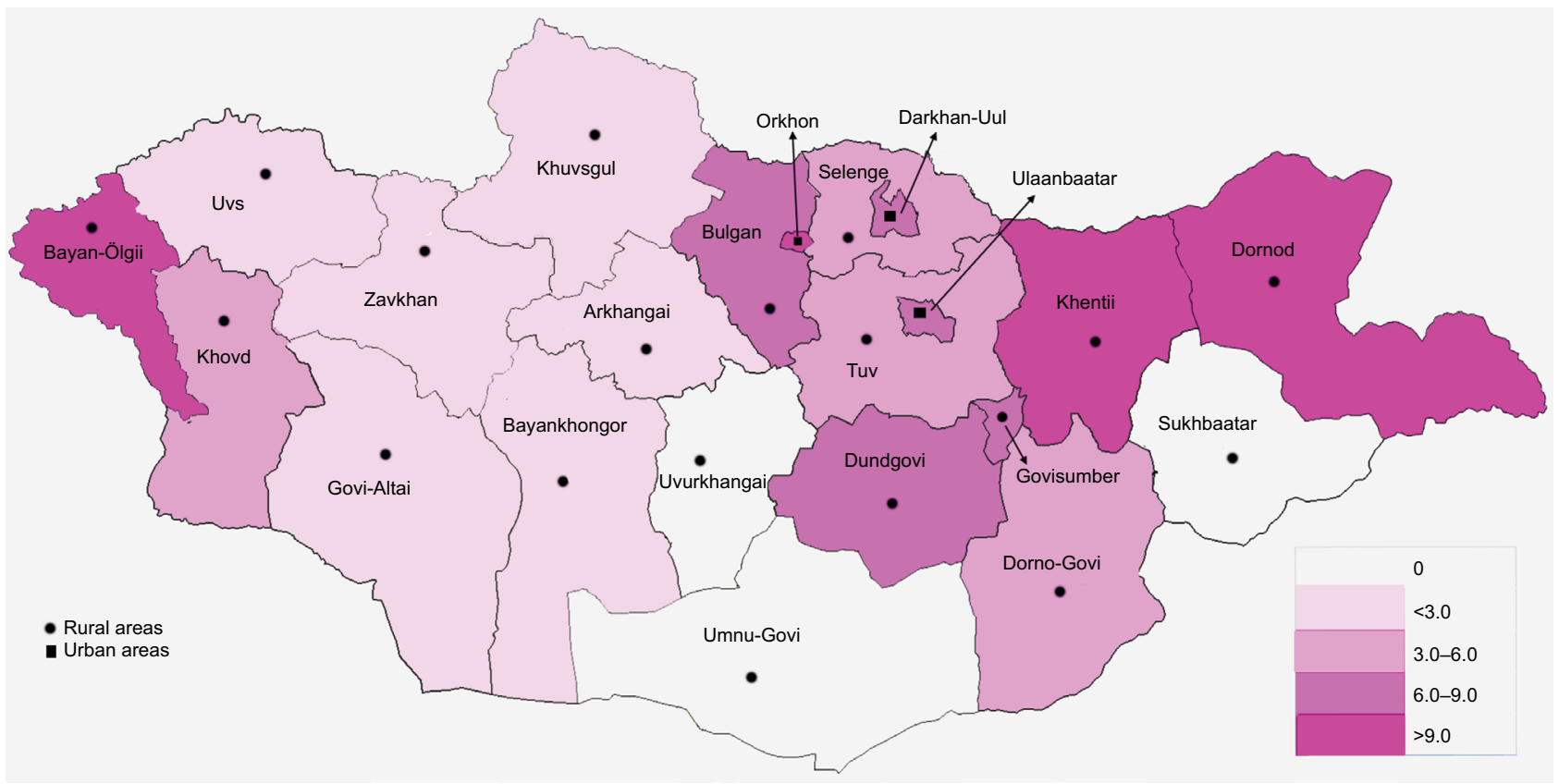

Figure 2 Age-standardized incidence rate by province, Mongolia, 2013.

Note: Data from Cancer Registry Data, National Cancer Center, Mongolia, 2009-2013.

available for collecting data across the whole of the country, data from rural areas may be impacted by limited health facilities, number of professionals and data distributions system compared with 3 urban locations in the country - the city of Ulaanbaatar (UB) and the larger provinces of Darkhan-Uul and Orkhon. A strong relationship between breast cancer and age has also been identified among Mongolian women with the highest incidence rate of 28.4/100,000 occurring among the 50-54 years old compared to 3.7 per 100,000 in the 15-39 age group. ${ }^{2}$ Although the peak age appears to be closer to other Asian countries, at least a decade difference is noted when compared with westernized states (Figure 3).

Asia in general has a low incidence of breast cancer compared with westernized countries. However, compared with Mongolia the disease is still common among Asian women ${ }^{6,16-20}$ and with a mean incidence of 29 per 100,000 in 2012, it is the most common cancer. ${ }^{2}$ Also when compared with countries such as the US, UK and Australia, the younger median age at diagnosis (40-50 years as opposed to 50-60 years) and the more progressed stage of the disease when diagnosed in Asia are quite different. ${ }^{17-19}$ However, due to lifestyle and reproductive changes in Asia, differences from westernized states to some extent are diminishing; for example, the incidence rates are increasing rapidly in the former, even though in absolute terms the rates for the time being remain low. ${ }^{20-22}$

In the westernized world, breast cancer is the most common cancer among women with a mean incidence of
90 per 100,000 in $2012 .{ }^{2}$ It has been observed that while age-standardized rates (ASRs) for breast cancer are higher, the rates are beginning to stabilize within developed countries unlike developing countries where breast cancer is continuing to emerge as an increasingly important health issue. ${ }^{23,24}$

\section{Breast cancer survival}

In Mongolia, data on survival of breast cancer are very limited. With the lack of an early detection program and limited diagnostic and therapeutic resources, breast cancer is diagnosed at late stages, leading to a 5-year survival rate of $57 \%$ that is considerably lower than that described in other countries as highlighted by the recent global study based on the data between 2005 and 2009. ${ }^{25}$ Similar findings were shown in the report from the NCC for the period 2003-2013, which found that the average survival time for Mongolian patients with breast cancer was 3.2 years. ${ }^{14}$ Also in Mongolia, $88.7 \%$ of women diagnosed with breast cancer are reported to die from the disease within 5 years ${ }^{14}$ which is significantly higher than westernized states where 5 -year survival is closer to $90 \%$. The limited access to health services in remote areas may play a role in delay of diagnosis resulting in poor survival outcome.

As a result of the advanced presentation of disease, the majority of breast cancer patients have radical mastectomy with axillary dissection combined with radiotherapy and chemotherapy, leading to a worse survival outcome compared 


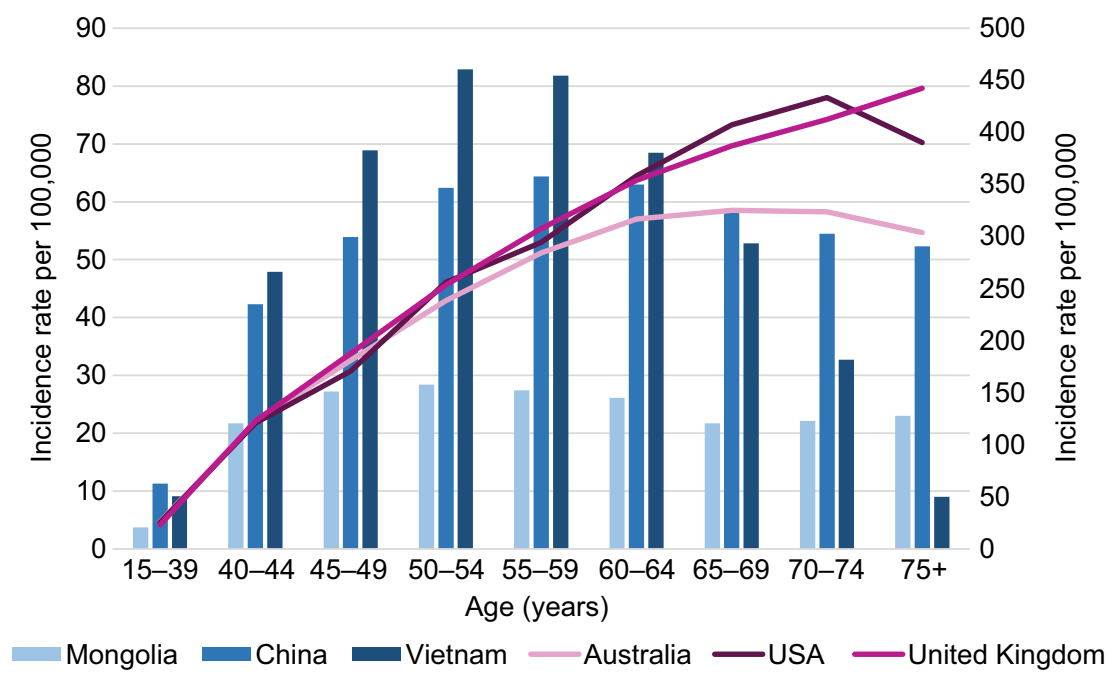

Figure 3 Age-specific incidence rate of female breast cancer, 2012.

Notes: The right axis indicates the incidence rates for Mongolia, China and Vietnam; the left axis indicates the incidence rates for Australia, USA and UK. Data from GLOBOCAN 2012. ${ }^{2}$

with the more developed treatments adopted elsewhere. Since early stage breast cancer is less frequent, the implementation of breast conserving surgery along with radiotherapy has only been conducted on a small proportion of patients. The use of radiation therapy remains low in Mongolia partially due to shortage of radiation oncologist and technologists. In addition, to treatment options, breast cancer survival can also be affected by other factors such as lifestyle, environmental, cultural and socioeconomic; ${ }^{26}$ however, information on these factors and their association with survival is not well understood in Mongolia.

In Asia, inconsistency of early detection programs and the varying levels of access to appropriate treatment have led to the survival rates varying considerably across the region. In Japan, Republic of Korea and People's Republic of China, for example, 5-year survival rates of $85 \%, 83 \%$ and $82 \%$, respectively, have been reported for invasive cancer cases during 2005-2009. ${ }^{25}$ More similar to Mongolia, survival rate is reported to be lower in Malaysia and India, where the rate is closer to $68 \%$ and $60 \%$, respectively. ${ }^{25}$ In addition, the majority of breast cancer patients from developing countries in Asia continue to be diagnosed at a relatively late stage and over $50 \%$ of all managed patients present with locally advanced cancer at the time of diagnosis. ${ }^{21,27,28}$ It is important to note that even when detection and treatment opportunities exist, other factors, including estrogen receptor (ER) status, preexisting chronic disease and ethnicity impact upon variation in survival. For example, ER-negative cancers are more commonly reported among Asian women, which is associated with poor prognosis. ${ }^{19}$
The introduction of mammogaphic screening in westernized states highlights a potential way forward for Mongolia and other developing Asian states. Screening aimed at asymptomatic patients has led to marked improvements in overall survival. For example, In 1991, screening was introduced in Australia and 5-year survival rate was shown to increase from $72 \%$ to $89 \%$ between the periods $1982-1995$ and 2006-2010. ${ }^{29}$ However, the impact of changes in prevalence of risk factors and advances in diagnosis and treatment on favorable survival outcome cannot be ruled out. Such factors impact on stage of diagnosis and treatment. The former is a critically important determinant of survival, particularly regarding tumor size and the involvement of lymph nodes. ${ }^{30,31}$

\section{Breast cancer mortality}

There is a paucity of quality data around mortality rates in Mongolia with some rural areas having no mortality data. A relatively recent national study ${ }^{13}$ demonstrated that $93.4 \%$ of the Mongolian women with breast cancer were diagnosed at advanced stages (Figure 4). The data that are available indicate that breast cancer is the 8th most common cause of cancer-related death in the country with age-standardized mortality rate of 2.7 per 100,000 in 2012. ${ }^{1}$ Comparisons with Asian and Westernized countries are demonstrated in Table 1. Similar to other developing Asian countries, mortality rates (and incidence numbers) are predicted to increase due to adoption of westernized lifestyle and recent increased detection and treatment facilities in Mongolia. 
100

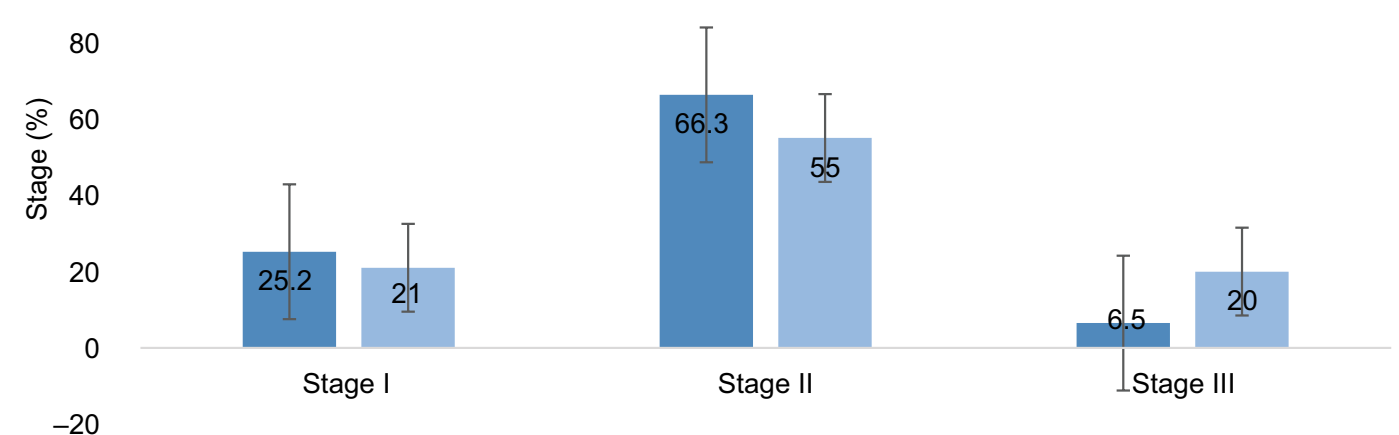

- Data from Enkhtur. ${ }^{13}$

Data from Angarmurun et al. ${ }^{14}$

Figure 4 Breast cancer by stage, Mongolia.

Table I Estimated breast cancer incidence and mortality by country, 2012

\begin{tabular}{llllll}
\hline Countries & \multicolumn{2}{l}{ Incidence } & & Mortality & \\
\cline { 2 - 3 } \cline { 5 - 6 } & Number & $\begin{array}{l}\text { ASR } \\
\text { (world) }\end{array}$ & Number & $\begin{array}{l}\text { ASR } \\
\text { (world) }\end{array}$ \\
\hline Mongolia & 125 & 9.4 & 50 & 1.6 \\
Asia & 650,983 & 29.1 & 231,013 & 6.4 \\
Westernized countries* & 127,016 & 89.5 & 26,906 & 7.3 \\
\hline
\end{tabular}

Notes: The rates are age-standardized per 100,000 female population. *North America, Western and Northern Europe, Australia/New Zealand. Data from GLOBOCAN 2012. ${ }^{2}$

Abbreviation: ASR, age-standardized rate.

Although the ASRs for breast cancer in Mongolia historically have been consistent, a recent important increase has been described by recent national mortality data between 2009 and 2013 (Figure 5) where the rate was almost doubled from $1.4 / 100,000$ in 2009 to $2.7 / 100,000$ in 2012. ${ }^{1}$ Interestingly, more than half of the deaths from breast cancer were registered in the capital city of UB in 2013. This figure is likely to be explained at least in part by population distributions since almost $50 \%$ of the Mongolian people live in $\mathrm{UB}^{32}$ and also by an urban lifestyle, which reflects westernized activities. Following the 2009-2012 increase, the mortality rate was declined to $1.6 / 100,000$ in 2013 . The explanation for this unusual change to the trend is unclear and may reflect incomplete data coverage.

Regional mortality variations in Mongolia, however, are not confined to the capital. Outside UB, variation in mortality rates is also evident with numbers being higher in rural provinces such as Bayan-Ölgii (4.4) and Dornod (4.0), while being lower in other regions such as Khuvsgul (0.8) (Figure 6). ${ }^{1}$ While inconsistent registry data may have contributed to these recorded variations, the stage of disease presentation is likely to be linked to these geographic variations.

While the rates are decreasing in many westernized nations, ${ }^{29,33,34}$ mortality rates continue to increase in Asian countries, aligning with rapid increases in incidence of breast cancer. ${ }^{19,22}$ In Asia, higher mortality rates are often observed in less developed countries despite these countries having low incidence rates. ${ }^{18,28,35} \mathrm{~A}$ variety of explanations have been proposed for these regional-dependent patterns around culture, socioeconomic factor, geographical isolation, inadequate diagnostic equipment and poor treatment facilities; however, a consistent casual parameter is delayed presentation of the disease. ${ }^{18,22,36}$

In developed countries, breast cancer is the 2nd leading cause of cancer-related mortality after lung cancer, resulting in 198,000 deaths (15.4\% of all cancer deaths) in 2012. ${ }^{2}$ Mortality rates for breast cancer have steadily declined in most westernized countries; $;^{37-40}$ however, based on 2012 data, globally it is estimated that more than half million women will die from this disease annually, highlighting that breast cancer is not only the disease of developed countries.

\section{Breast screening}

Currently, in Mongolia, there is no population-based breast cancer screening; instead in 2010, guidelines were established for the prevention and management of the disease. As outlined in the guidelines, mammography is not recommended for early detection due to the relatively low incidence rates, limited resources for equipment and sparsely distributed populations in Mongolia. ${ }^{41}$ Therefore, clinical examination is the front line tool used for early 
60

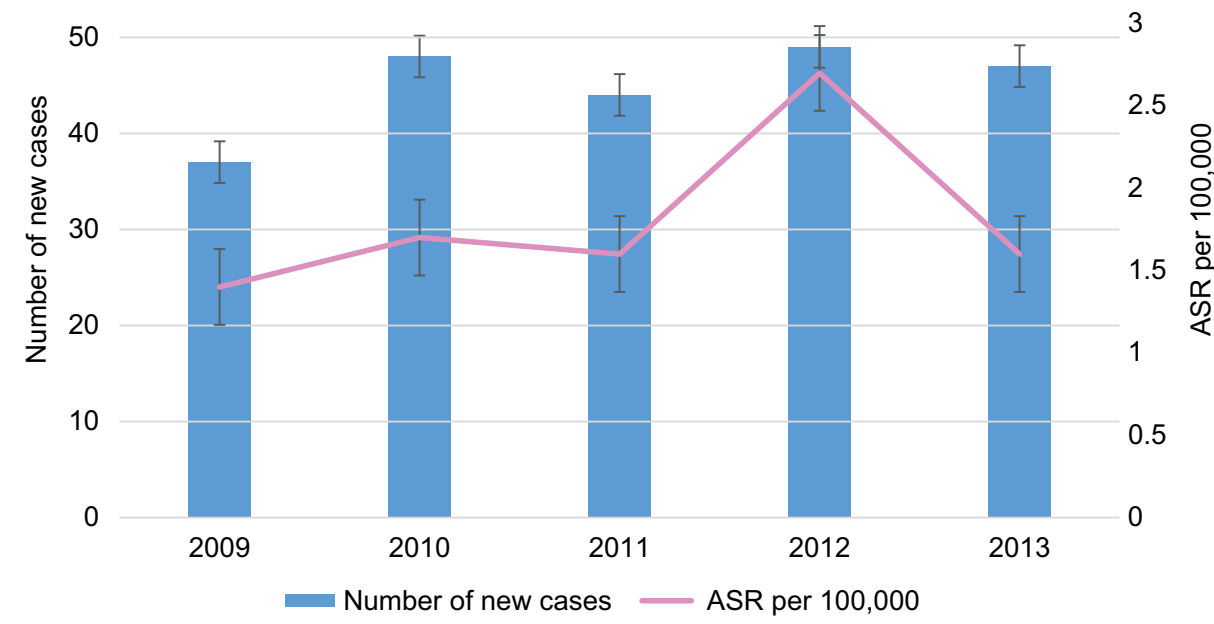

3.5

8 . 
presentations in Mongolia need to be carried out so that a country-specific solution can be found.

In Asia, compared with the Western nations, breast cancer screening is not so widespread. The effectiveness of mammographic screening in Asia is the subject of debate due to the low incidence of breast cancer across the region, the prevalence of smaller breasts and denser breast parenchyma among Asian women. ${ }^{43,44}$ Nonetheless, some Asian countries have adopted mammography for mass screening, such as Singapore, Japan and Taiwan, where some favorable outcomes have been reported. ${ }^{45-48}$ In Singapore for example (the first Asian country to introduce screening for 50-69 years old in 2002), the overall invasive cancer detection rate was reported to be 7.92 per 1000 women screened during 2002-2009 and a $12 \%$ increased rate of early stage cancers was recorded compared with prescreening period (before 2001). ${ }^{48}$

In developed countries, breast screening with mammography is a well-established approach for the early detection of breast cancer and many experts agree that the benefit of mammography outweighs the harms. In particular, mammography is more accurate in older women than in young women. ${ }^{49,50}$ The overall impact of screening is debated with reported reductions in mortality from $15 \%$ to $58 \% .^{50-56}$

\section{Risk factor}

The causes for breast cancer are not fully understood but women with certain risk factors are more likely to develop the disease than others. In Mongolia, the risk factors associated with breast cancer are understudied. The only available case-control study ${ }^{13}$ involved 522 breast cancer patients and was locally published in 2009. Similar to other countries, this limited evidence proposes the following risk factors: reproductive factors including early menarche, irregular menstrual cycles, nulliparity and obesity; induced abortion, which was aligned with a recent Chinese meta-analysis; ${ }^{57}$ and various disease states including ovarian chronic inflammation and cysts and uterine fibroids. ${ }^{13}$ It is also interesting to note that ethnic minority groups are expected to have low rates of incidence and mortality since these women generally adhere to more traditional lifestyles compared with their westernized counterparts; however, the opposite pattern was observed in Mongolia, which suggests a uniqueness around genetic and risk factors. While the aforementioned factors have been shown to be relevant to Mongolia, other important parameters reported for other countries such as family history, lifestyle factors and hormone replacement treatment (HRT) are currently poorly understood in Mongolia.
Current knowledge regarding breast presentation remains poor, which demands a better understanding of this disease among Mongolian women. For example, mammographic breast density has been shown to be one of the most important risk factors in westernized populations but nothing is known around this feature among Mongolian women. Westernized women with high density have been shown to have 4- to 6-fold increased lifetime risk of breast cancer. ${ }^{58-61}$ This is a feature that can be assessed from mammographic examinations and while mammography occurs in Mongolia, little data are gathered on density distributions, particularly across ethnicity, age, body mass index and menopausal status. The absence of information is not the case across Asia; for example in China, breasts are known to be fattier than in American women in older age but denser in young age. ${ }^{62}$ The importance of understanding this feature for identifying risk and indeed for determining the optimal method of diagnostic imaging is emphasized so that prevention, early detection and intervention of the disease can be facilitated.

In Asia, while the prevalence and distribution of risk factors among Asian women vary between countries and studies, some common features have been noted in westernized studies. ${ }^{19,63-66}$ A recent Asian meta-analysis summarized that more than 3 abortions, family history, late age at first live birth (over 30 years old), smoking, no breastfeeding, alcohol consumption and longer usage of HRT are associated with breast cancer among Asian women. ${ }^{67}$ Other risk factors reported among these women include body fat, which reduces and increases the risk of breast cancer in premenopausal and postmenopausal women, respectively. ${ }^{68,69}$ Uniquely to this region, however, a higher intake of soy food with their associated protective effect for breast cancer has been reported among Asian women, ${ }^{70,71}$ and in China, consumption of green tea was reported to be associated with risk of breast cancer, ${ }^{72}$ whereas this was not observed among Japanese women. ${ }^{73}$

In developed countries, certain lifestyle activities, westernized diets, high socioeconomic status, physical inactivity and obesity are reported to be associated with breast cancer risk in these regions. ${ }^{74-76}$ For example, a European cohort study revealed that an increased risk of $31 \%$ for breast cancer is strongly associated with obesity among postmenopausal women. ${ }^{76}$ Family history and gene mutations such as BRCA1 and BRCA2 are also well known, established risk factors. ${ }^{77-81}$ In general, hormonal factors are different in prevalence between breast cancer subtypes; however, 
hormone receptor-positive tumors were consistently being reported among Western women. ${ }^{82,83}$ Westernized women also tend to have shorter breastfeeding period and low parity compared with Asian women, resulting in high risk for developing breast cancer. ${ }^{84,85}$

\section{In summary, what is distinct about Mongolia?}

With the limited available data, this review is the first attempt to describe the current situation of breast cancer in Mongolia while investigating different aspects of the disease. It is evident that breast cancer incidence rate in Mongolia is among the lowest in the world and there are several possible explanations that have been considered in the above sections and relate to lifestyle, health policy and quality of registry data. With regard to lifestyle, reproductive activities such as longer breast feeding ${ }^{86}$ and higher number of full-term pregnancies probably play a significant role, and as described within the only peerreviewed publication ${ }^{12}$ on the topic, dietary habits around high-level consumption of tea, meat and dairy product may also be key. However, absence of a breast screening program must also be a contributory factor particularly since it is evident that rates of breast cancer have increased in those Asian countries that have recently introduced formal screening programs. ${ }^{48,87}$ Finally, reliability of cancer registry data cannot be excluded as incomplete data exist. Until screening procedures are formalized and accurate registry data become available, the importance of breast cancer to Mongolia cannot be fully appreciated. What is appreciated is that late disease presentation, poor survival and high mortality demand a coordinated effort between researchers, clinicians and health strategists to ensure that Mongolian women do not continue to suffer poorer health outcomes compared with their neighbors and westernized counterparts.

\section{Conclusion}

While breast cancer incidence is low in Mongolia compared with other Asian countries and westernized states, incidence rates are gradually increasing. Early detection with optimal imaging methods may be a key to minimizing the impact of this disease on Mongolian women; however, not enough is known about the type of cancer being presented, the regional distribution of the disease and the type of women most effected, which is needed to facilitate allocation of limited resources.

\section{Acknowledgment}

We would like to thank Professor Asai Ramish, senior radiologist at the NCC in Mongolia, for his collaboration.

\section{Disclosure}

The authors report no conflicts of interest in this work.

\section{References}

1. NCC. National Cancer Registry, 2009-2013. Mongolia: National Cancer Center; 2014

2. Ferlay J, Soerjomataram I, Dikshit R, et al. Cancer incidence and mortality worldwide: sources, methods and major patterns in GLOBOCAN 2012. Int J Cancer. 2015;136(5):E359-E386.

3. Sandagdorj T, Sanjaajamts E, Tudev U, Oyunchimeg D, Ochir C, Roder D. Cancer incidence and mortality in Mongolia - National Registry Data. Asian Pac J Cancer Prev. 2010;11(6):1509-1514.

4. Chimed T, Sandagdorj T, Znaor A, et al. Cancer incidence and cancer control in Mongolia: results from the National Cancer Registry 2008-12. Int J Cancer. 2017;140(2):302-309.

5. Torre LA, Bray F, Siegel RL, Ferlay J, Lortet-Tieulent J, Jemal A. Global cancer statistics, 2012. CA Cancer J Clin. 2015;65(2):87-108.

6. Parkin DM, Fernández LM. Use of statistics to assess the global burden of breast cancer. Breast J. 2006;12(Suppl 1):S70-S80.

7. Coughlin SS, Ekwueme DU. Breast cancer as a global health concern. Cancer Epidemiol. 2009;33(5):315-318.

8. Kanavos P. The rising burden of cancer in the developing world. Ann Oncol. 2006;17(Suppl 8):viii15-viii23.

9. Anderson BO, Ilbawi AM, El Saghir NS. Breast cancer in low and middle income countries (LMICs): a shifting tide in global health. Breast $J$. 2015;21(1):111-118.

10. Curado MP. Breast cancer in the world: incidence and mortality. Salud Publica Mex. 2011;53(5):372-384.

11. Li J, Shao Z. Mammography screening in less developed countries. Springerplus. 2015;4:615.

12. Troisi R, Altantsetseg D, Davaasambuu G, et al. Breast cancer incidence in Mongolia. Cancer Causes Control. 2012;23(7):1047-1053.

13. Enkhtur A. The Risk Factors for Developing Breast Cancer in Mongolia [PhD thesis]. Health Science University of Mongolia; 2009.

14. Angarmurun D, Batzorig B, Undram L, Gantuya D, Chimedsuren O, Avirmed D. Breast cancer survival in Mongolian women. Open Access Library Journal. 2014;1:1-5.

15. Fan L, Strasser-Weippl K, Li JJ, et al. Breast cancer in China. Lancet Oncol. 2014;15(7):e279-e289.

16. Jemal A, Bray F, Center MM, Ferlay J, Ward E, Forman D. Global cancer statistics. CA Cancer J Clin. 2011;61(2):69-90.

17. Huang CS, Lin CH, Lu YS, Shen CY. Unique features of breast cancer in Asian women-breast cancer in Taiwan as an example. J Steroid Biochem Mol Biol. 2010;118(4-5):300-303.

18. Agarwal G, Pradeep PV, Aggarwal V, Yip CH, Cheung PS. Spectrum of breast cancer in Asian women. World J Surg. 2007;31(5):1031-1040.

19. Leong SP, Shen ZZ, Liu TJ, et al. Is breast cancer the same disease in Asian and Western countries? World J Surg. 2010;34(10): 2308-2324.

20. Yip CH. Breast cancer in Asia. Methods Mol Biol. 2009;471:51-64.

21. Yip CH, Buccimazza I, Hartman M, Deo SV, Cheung PS. Improving outcomes in breast cancer for low and middle income countries. World J Surg. 2015;39(3):686-692.

22. Green M, Raina V. Epidemiology, screening and diagnosis of breast cancer in the Asia-Pacific region: current perspectives and important considerations. Asia Pac J Clin Oncol. 2008;4(Suppl 3):S5-S13.

23. Youlden DR, Cramb SM, Yip CH, Baade PD. Incidence and mortality of female breast cancer in the Asia-Pacific region. Cancer Biol Med. 2014;11(2):101-115. 
24. Hou N, Huo D. A trend analysis of breast cancer incidence rates in the United States from 2000 to 2009 shows a recent increase. Breast Cancer Res Treat. 2013;138(2):633-641.

25. Allemani C, Weir HK, Carreira H, et al; CONCORD Working Group. Global surveillance of cancer survival 1995-2009: analysis of individual data for 25,676,887 patients from 279 population-based registries in 67 countries (CONCORD-2). Lancet. 2015;385(9972):977-1010.

26. Bhoo-Pathy N, Hartman M, Yip CH, et al. Ethnic differences in survival after breast cancer in South East Asia. PLoS One. 2012;7(2):e30995.

27. Shulman LN, Willett W, Sievers A, Knaul FM. Breast cancer in developing countries: opportunities for improved survival. JOncol. 2010;2010:595167.

28. Agarwal G, Ramakant P, Forgach ER, et al. Breast cancer care in developing countries. World J Surg. 2009;33(10):2069-2076.

29. AIHW. Breast Cancer in Australia: an Overview. Canberra: Australian Institute of Health and Welfare \& Cancer Australia; 2012.

30. AIHW. Breast Cancer Survival by Size and Nodal Status in Australia. Canberra: National Breast Cancer Centre \& Australasian Association of Cancer Registries; 2007.

31. Walters S, Maringe C, Butler J, et al. Breast cancer survival and stage at diagnosis in Australia, Canada, Denmark, Norway, Sweden and the UK, 2000 2007: a population-based study. Br J Cancer. 2013;108(5):1195-1208.

32. NSO. Population by provinces, National Statistics Office of Mongolia, [Internet]. 2015; Available from: http://www.en.nso.mn/index.php. Accessed November 21, 2016

33. AIHW. Australian Cancer Incidence and Mortality (ACIM) Books: Breast Cancer. 2015. Available from: http://www.aihw.gov.au/acimbooks. Accessed November 21, 2016.

34. ACS. Breast Cancer Facts \& Figures 2013-2014. Atlanta, GA: American Cancer Society, Inc; 2013.

35. Binns C, Low WY, Lee MK. Breast cancer: an increasing public health problem in the Asia Pacific region. Asia Pac J Public Health. 2013;25(5):364-367.

36. Bhoo-Pathy N, Yip CH, Hartman M, et al. Breast cancer research in Asia: adopt or adapt Western knowledge? Eur J Cancer. 2013;49(3):703-709.

37. Bosetti C, Bertuccio P, Malvezzi M, et al. Cancer mortality in Europe, 2005-2009, and an overview of trends since 1980. Ann Oncol. 2013;24(10): 2657-2671.

38. Australian Institute of Health and Welfare. Cancer in Australia: actual incidence data from 1991 to 2009 and mortality data from 1991 to 2010 with projections to 2012. Asia Pac J Clin Oncol. 2013;9(3):199-213.

39. Jatoi I, Miller AB. Why is breast-cancer mortality declining? Lancet Oncol. 2003;4(4):251-254.

40. Berry DA, Cronin KA, Plevritis SK, et al; Cancer Intervention and Surveillance Modeling Network (CISNET) Collaborators. Effect of screening and adjuvant therapy on mortality from breast cancer. $N E n g l$ J Med. 2005;353(17):1784-1792.

41. MOH. National Cancer Control Program 2007-2017. Ulaanbaatar: Mongolia Ministry of Health; 2007.

42. WHO. Mongolia Health System Review, Health Systems in Transition. Geneva, Switzerland: World Health Organisation; 2013.

43. Tan SM, Evans AJ, Lam TP, Cheung KL. How relevant is breast cancer screening in the Asia/Pacific region? Breast. 2007;16(2):113-119.

44. Wong IO, Kuntz KM, Cowling BJ, Lam CL, Leung GM. Cost effectiveness of mammography screening for Chinese women. Cancer. 2007; 110(4):885-895.

45. Yeoh KG, Chew L, Wang SC. Cancer screening in Singapore, with particular reference to breast, cervical and colorectal cancer screening. J Med Screen. 2006;13(Suppl 1):S14-S19.

46. Morimoto T, Sasa M, Yamaguchi T, Kondo H, Akaiwa H, Sagara Y. Breast cancer screening by mammography in women aged under 50 years in Japan. Anticancer Res. 2000;20(5C):3689-3694.

47. Wu GH, Chen LS, Chang KJ, et al; Taiwan Breast Cancer Screening Group. Evolution of breast cancer screening in countries with intermediate and increasing incidence of breast cancer. J Med Screen. 2006; 13(Suppl 1):S23-S27.

48. Loy EY, Molinar D, Chow KY, Fock C. National breast cancer screening programme, Singapore: evaluation of participation and performance indicators. J Med Screen. 2015;22(4):194-200.
49. Pace LE, Keating NL. A systematic assessment of benefits and risks to guide breast cancer screening decisions. JAMA. 2014;311(13): $1327-1335$.

50. Henderson LM, O’Meara ES, Braithwaite D, Onega T, Breast Cancer Surveillance Consortium. Performance of digital screening mammography among older women in the United States. Cancer. 2015;121(9): 1379-1386.

51. Nelson HD, Tyne K, Naik A, Bougatsos C, Chan BK, Humphrey L; U.S. Preventive Services Task Force. Screening for breast cancer: an update for the U.S. Preventive Services Task Force. Ann Intern Med. 2009;151(10):727-737, W237-W242.

52. AIHW. Breast Screen Australia Monitoring Report 2011-2012. Canberra: Australian Institute of Health and Welfare; 2014.

53. Paap E, Verbeek AL, Botterweck AA, et al. Breast cancer screening halves the risk of breast cancer death: a case-referent study. Breast. 2014;23(4):439-444.

54. Kalager M, Løberg M, Bretthauer M, Adami HO. Comparative analysis of breast cancer mortality following mammography screening in Denmark and Norway. Ann Oncol. 2014;25(6):1137-1143.

55. Christiansen P, Vejborg I, Kroman N, et al. Position paper: breast cancer screening, diagnosis, and treatment in Denmark. Acta Oncol. 2014; 53(4):433-444.

56. Myers ER, Moorman P, Gierisch JM, et al. Benefits and harms of breast cancer screening: a systematic review. JAMA. 2015;314(15):1615-1634.

57. Huang Y, Zhang X, Li W, et al. A meta-analysis of the association between induced abortion and breast cancer risk among Chinese females. Cancer Causes Control. 2014;25(2):227-236.

58. Boyd NF, Guo H, Martin LJ, et al. Mammographic density and the risk and detection of breast cancer. N Engl J Med. 2007;356(3):227-236.

59. Boyd N, Martin L, Chavez S, et al. Breast-tissue composition and other risk factors for breast cancer in young women: a cross-sectional study. Lancet Oncol. 2009;10(6):569-580.

60. Boyd NF, Martin LJ, Bronskill M, Yaffe MJ, Duric N, Minkin S. Breast tissue composition and susceptibility to breast cancer. J Natl Cancer Inst. 2010;102(16):1224-1237.

61. McCormack VA, Silva IDS. Breast density and parenchymal patterns as markers of breast cancer risk: a meta-analysis. Cancer Epidemiol Biomarkers Prev. 2006;15(6):1159-1169.

62. Dai H, Yan Y, Wang P, et al. Distribution of mammographic density and its influential factors among Chinese women. Int J Epidemiol. 2014;43(4):1240-1251.

63. Gibson LJ, Héry C, Mitton N, et al. Risk factors for breast cancer among Filipino women in Manila. Int J Cancer. 2010;126(2):515-521.

64. Matalqah L, Radaideh K, Yusoff ZM, Awaisu A. Predictors of breast cancer among women in a northern state of Malaysia: a matched casecontrol study. Asian Pac J Cancer Prev. 2011;12(6):1549-1553.

65. Mizota Y, Yamamoto S. Prevalence of breast cancer risk factors in Japan. Jpn J Clin Oncol. 2012;42(11):1008-1012.

66. Lee SM, Park JH, Park HJ. Breast cancer risk factors in Korean women: a literature review. Int Nurs Rev. 2008;55(3):355-359.

67. Tao P, Hu YY, Huang Y, Li JY. [Risk factors of breast cancer in Asian women: a meta-analysis]. Zhonghua Liu Xing Bing Xue Za Zhi. 2011; 32(2):164-169.

68. Baer HJ, Tworoger SS, Hankinson SE, Willett WC. Body fatness at young ages and risk of breast cancer throughout life. Am J Epidemiol. 2010;171(11):1183-1194.

69. Wu AH, Yu MC, Tseng CC, Pike MC. Body size, hormone therapy and risk of breast cancer in Asian-American women. Int $J$ Cancer. 2007;120(4):844-852.

70. Wu AH, Yu MC, Tseng CC, Pike MC. Epidemiology of soy exposures and breast cancer risk. Br J Cancer. 2008;98(1):9-14.

71. Trock BJ, Hilakivi-Clarke L, Clarke R. Meta-analysis of soy intake and breast cancer risk. J Natl Cancer Inst. 2006;98(7):459-471.

72. Dai Q, Shu XO, Li H, et al. Is green tea drinking associated with a later onset of breast cancer? Ann Epidemiol. 2010;20(1):74-8.

73. Iwasaki M, Mizusawa J, Kasuga Y, et al. Green tea consumption and breast cancer risk in Japanese women: a case-control study. Nutr Cancer. 2014;66(1):57-67. 
74. Hamajima N, Hirose K, Tajima K, Collaborative Group on Hormonal Factors in Breast Cancer. Alcohol, tobacco and breast cancer - collaborative reanalysis of individual data from 53 epidemiological studies, including 58,515 women with breast cancer and 95,067 women without the disease. Br J Cancer. 2002;87(11):1234-1245.

75. Tseng M, Byrne C, Evers KA, Daly MB. Dietary intake and breast density in high-risk women: a cross-sectional study. Breast Cancer Res. 2007;9(5):R72.

76. Lahmann PH, Hoffmann K, Allen N, et al. Body size and breast cancer risk: findings from the European prospective investigation into cancer and nutrition (EPIC). Int J Cancer. 2004;111(5):762-771.

77. Boyle P, Levin B. World Cancer Report 2008. Lyon: International Agency for Research on Cancer; 2008.

78. Trentham-Dietz A, Sprague BL, Hampton JM, et al. Modification of breast cancer risk according to age and menopausal status: a combined analysis of five population-based case-control studies. Breast Cancer Res Treat. 2014;145(1):165-175.

79. Mavaddat N, Peock S, Frost D, et al; EMBRACE. Cancer risks for BRCA1 and BRCA2 mutation carriers: results from prospective analysis of EMBRACE. J Natl Cancer Inst. 2013;105(11):812-822.

80. Welsh ML, Buist DS, Aiello Bowles EJ, Anderson ML, Elmore JG, Li CI. Population-based estimates of the relation between breast cancer risk, tumor subtype, and family history. Breast Cancer Res Treat. 2009; 114(3):549-558.
81. Howard AF, Balneaves LG, Bottorff JL, Rodney P. Preserving the self: the process of decision making about hereditary breast cancer and ovarian cancer risk reduction. Qual Health Res. 2011;21(4): 502-519.

82. Li CI, Beaber EF, Tang MT, Porter PL, Daling JR, Malone KE. Reproductive factors and risk of estrogen receptor positive, triple-negative, and HER2-neu overexpressing breast cancer among women 20-44 years of age. Breast Cancer Res Treat. 2013;137(2):579-587.

83. Anderson KN, Schwab RB, Martinez ME. Reproductive risk factors and breast cancer subtypes: a review of the literature. Breast Cancer Res Treat. 2014;144(1):1-10.

84. Kobayashi S, Sugiura H, Ando Y, et al. Reproductive history and breast cancer risk. Breast Cancer. 2012;19(4):302-308.

85. Collaborative Group on Hormonal Factors in Breast Cancer. Breast cancer and breastfeeding: collaborative reanalysis of individual data from 47 epidemiological studies in 30 countries, including 50302 women with breast cancer and 96973 women without the disease. Lancet. 2002; 360(9328): 187-195.

86. Dickson I. The Association Between Breastfeeding Practices in Mongolia and Geographical Location of the Mother and Child [thesis]. Seattle (WA): University of Washington; 2012.

87. Wu TY, Chung S, Yeh MC, Chang SC, Hsieh HF, Ha SJ. Understanding breast cancer screening practices in Taiwan: a country with universal health care. Asian Pac J Cancer Prev. 2012;13(9):4289-4294.
Breast Cancer - Targets and Therapy

\section{Publish your work in this journal}

Breast Cancer - Targets and Therapy is an international, peerreviewed open access journal focusing on breast cancer research, identification of therapeutic targets and the optimal use of preventative and integrated treatment interventions to achieve improved outcomes, enhanced survival and quality of life for the cancer patient.

\section{Dovepress}

The manuscript management system is completely online and includes a very quick and fair peer-review system, which is all easy to use. Visit http://www.dovepress.com/testimonials.php to read real quotes from published authors. 